Boise State University

ScholarWorks

Social Work Faculty Publications and Presentations

School of Social Work

$10-1-2012$

\title{
Better Together: Expanding Rural Partnerships to Support Families
}

Harriet Shaklee

University of Idaho

Jeri Bigbee

University of California - Davis

Misty Wall

Boise State University 


\title{
Better Together: Expanding Rural Partnerships to Support Families
}

\author{
Harriet Shaklee \\ University of Idaho
}

\author{
Jeri Bigbee \\ University of California-Davis
}

\author{
Misty Wall \\ Boise State University
}

\begin{abstract}
Chronic shortages of health, social service, and mental health professionals in rural areas necessitate creative partnerships in support of families. Cooperative extension professionals in Family and Consumer Sciences and community health nurses are introduced as trusted professionals in rural communities who can bring critical skills to human services teams. Multidisciplinary prevention programs offer particularly good contexts for county extension educators and community health nurses to work in collaboration with social workers. The case of grandparents raising grandchildren illustrates the critical roles that can be filled by professionals in these two fields to extend the reach of family support programs.
\end{abstract}

Keywords: Rural, prevention, families, grandparents, cooperative extension, community nursing

Rural and frontier areas experience chronic shortages of health, mental health and social work clinicians. Sixty-six percent of areas federally designated as mental health profession shortage areas are rural. Particularly limited are those specializing in services to children and older adults (National Advisory Committee on Rural Health and Human Services, 2008). A 2004 workforce survey found that $80 \%$ of social workers who work with children and adolescents serve in urban areas, while just 3\% work in rural communities (Center for Health Workforce Studies, 2006). Given these limitations in access to mental health professionals in rural areas, it is not be surprising that use of mental health services is lower in rural than urban areas (Gamm, Stone, and Pittman, 2003).

Research findings suggest that social service needs of rural families would be just as great, if not greater, than those of metro families. Research consistently shows poverty to be a strong risk factor for children, and poverty is particularly pronounced for rural children. Persistent poverty is associated with the most negative child outcomes, that is, locations in which $20 \%$ or more of residents are in poverty for a period of 30 or more years. Eighty-eight percent of areas of persistent poverty in the U.S. are rural counties (National Advisory Committee on Rural Health and Human Services, 2008).

Substance abuse is also more common in rural areas, starting in the teenage years and continuing through adulthood (National Advisory Committee on Rural Health and Human Services, 2007). Abuse of alcohol, methamphetamine, narcotics and prescription painkillers are of particular concern. Nearly twice as many young adults (18-25 years) in rural areas abuse Oxycontin and methamphetamine, compared to urban age mates, and $48 \%$ of young adults in larger rural areas (population 20,000 or more) reported engaging in binge drinking (i.e. five or more drinks on a single occasion, Maine Rural Health Research Center, 2007). Yet there are fewer detox and treatment facilities per capita in rural than in urban areas. (National Advisory Committee on Rural Health and Human Services, 2007).

The American Psychological Association (2012) highlights several signs that many rural families are overstressed. Rural communities include sizeable populations who are at elevated risk for mental health concerns, especially older residents and people who are chronically ill. The National Behavioral Health Survey shows a significantly higher rate of major depression among rural populations, and suicide is the second leading cause of death in rural areas (American Psychological Association, 2012).

The recent influx of immigrants and refugees to some rural communities can also test the limits of rural human services. First generation immigrants are challenged to learn the language and ways of their new country, while human services professionals must learn to adjust their programs to better accommodate the traditions of the new arrivals. Refugee groups come to U.S. communities after extended periods of trauma, and often require culturally sensitive social services and counseling (Martinez-Brawley, 2009). 
The recession of 2007-11 has further burdened rural social service programs. Tax revenues diminished as the employment rolls shrank, family purchasing power contracted, and property values declined - all major sources of public funds. As a result, government-based social services were targets of budget cuts, reducing programs for family support. Nonprofits dedicated to family well-being were threatened as well, as grant opportunities were curtailed and foundation endowments lost value (Gais, 2010; McDaid \& Knapp, 2010; Wise, 2009).

Financial stress for programs was mirrored in stress for families, who struggled with job loss, reduced incomes, home foreclosures, forced moves, homelessness, and an inability to meet nutritional, health, and educational needs of family members (Shaklee \&Brown, 2009). Economic downturn can result in a perfect storm for health and social services, as program resources shrink just as family needs grow.

Limited resources must be used carefully when need exceeds capacity, including leveraging existing resources by collaborating with allied organizations and professions. Multidisciplinary teams of mental health professionals are often employed to help communities stretch program resources (National Advisory Committee on Rural Health and Human Services, 2005). One successful collaborative approach is the wrap-around model, in which professionals from complementary social service and mental health disciplines come together to meet the varied needs of individual families (e.g. Carney \& Buttel, 2003)

When resources are taxed to the limit, rural social workers may find that other trusted professionals in the community can further extend the reach of human service programs. County cooperative extension educators and community nurses are introduced as natural partners in promoting family well-being in rural communities.

\section{Cooperative Extension}

Each state has one or more universities designated as a land grant institution, endowed by the Smith-Lever Act of 1914 with a mission to provide research-based practical information to the public. Over the past 100 years, the resulting cooperative extension system has established a strong presence in communities throughout the nation. With its historical roots in agriculture and rural concerns, extension programming is a particularly trusted resource in small town and rural areas (U.S. Department of Agriculture, 2011).

The cooperative extension service operates extensive programs throughout the nation, supported by funds from the U.S. Department of Agriculture in conjunction with state and county monies. Local university extension programming emanates from county or regional offices in response to community needs. Strong links to campusbased university research facilities and faculty keep county educators updated in content (U.S. Department of Agriculture, 2011).

Most relevant to human services are the many county extension educators representing Family and Consumer Sciences (FCS), with its interdisciplinary approach to family well-being. FCS extension educators lead evidencebased programs in family relations, parenting, home safety, youth development, 4-H, fitness, nutrition, diabetes management, and caregiver support Extension emphasizes the translation of research findings into practices that families can use on an ongoing basis. Target audiences include marginalized groups and new arrivals, as well as mainstays of the community. Programs are developed to accommodate the needs of limited-education and low income audiences (Hill and Parker, 2005; U.S. Department of Agriculture, 2011).

\section{Community Health Nursing}

Community health nurses are also natural partners for family support programming. Community health nursing is a specialty area that provides care to individuals, families and communities, based on a strong health promotion and advocacy approach. Since the early $20^{\text {th }}$ century, this area of nursing practice has a tradition of creatively and collaboratively addressing the needs of rural populations through such innovative programs as the Frontier Nursing Service and the Red Cross Rural Nursing Service (Bigbee \& Crowder, 1985).

Today, community health nurses practice in a variety of community-based settings, including public health departments, community clinics, schools, and home health/hospice agencies. An increasing percentage of nurses work in community health settings (as opposed to hospitals), particularly in rural and frontier areas. Like extension educators, nurses enjoy strong respect and trust among rural community residents (Bigbee, 1993). 
Community health nurses and cooperative extension professionals share common perspectives and approaches, and collaboration between the groups can be particularly productive (Condo \& Martin, 2002; Jenkins, 1991; Hall, Wimberly, Hall, Pfriemer, Hubbard, Stacy, \& Gilbert, 2005; Gray, 1990). One such nursing-extension collaboration in an isolated rural Idaho county integrated programs in health, safety and family support (Bigbee, Hampton, Blanford, \& Ketner 2009). The authors conclude that "unlike some other practice settings, interdisciplinary cooperation is the norm in rural and frontier communities, based on the culture of strong community ties, the importance of social capital, and the need to maximize limited resources" (Bigbee et al., 2009, p. 196). From this perspective, a partnership between social workers, nurses, and cooperative extension professionals would be a logical extension of this "better together" rural ethic in addressing the human service needs of rural populations during challenging economic times.

\section{Prevention Models and Community Partnerships}

Research has amply documented the effectiveness of prevention strategies in working with at-risk families, in areas as diverse as child abuse prevention, school engagement, and teen pregnancy prevention (see Bugenthal, Ellerson, Lin, Rainey, Kokotovic, \& O'Hara, 2002; Goldberg, Frank, Bekenstein, Garriety, \& Ruiz, 2011; Prinz, Sanders, Shapiro, Whitaker, \& Lutzker, 2009; or Scribano, 2010 for example studies). Prevention programs work with families who evidence risk factors of concern, but often have not yet shown the problematic behavior. Prevention programs are widely distributed among populations at risk (e.g. single parent, poverty-level income, high school dropout), rather than focusing on the smaller pool of families who actually develop the problem behaviors (e.g. family violence or substance abuse). Since consequences can be so severe and treatment so intensive for children and adults in families who exhibit dysfunctional behaviors, the more broadly-based prevention strategy is often cost effective, with more positive outcomes for families (e.g. DeBord, 2005).

Current research also supports an integrated mental-plus-physical health approach, based on several studies showing that family life stressors compromise later physical as well as mental health outcomes (Campbell, Greeson, Bybee, \& Raja, 2008; Lanier, Jonson-Reid, Stahlschmidt, Drake, \& Constantino, 2010; Maniglio, 2010). For example, negative outcomes as diverse as youth risk taking, early pregnancy, educational underachievement, and poor health and mental health outcomes are linked to childhood poverty, supporting anti-poverty measures as a core approach to family support. The stresses of child abuse and neglect have also been linked to indicators of poor physical health well into adulthood, in addition to the mental health concerns more traditionally linked to early abuse. Such findings demonstrate the broad potential impact of effective family violence prevention programs. These findings illustrate the unity of physical and mental systems for individuals and families, and underscore the importance of collaboration between health care and mental health programs under a shared human services umbrella.

\section{Prevention Strategies are Multidisciplinary}

Prevention approaches to family well-being reach beyond traditional generalist and clinical social work strategies in engaging families. In particular, major components of prevention are educational and motivational. Families may need to reshape a problem pattern of behavior toward habits more likely to allow them to attain their desired outcomes. For example positive discipline strategies may be more effective in promoting the achievement success a mother would like her child to experience, so that she will need to forego a family tradition of spanking in favor of alternative approaches. Program challenges include communicating information effectively so the mother understands it, working with her on a behavior change strategy, as well as motivating her to make the change.

These are challenges well explored by research in adult education, replete with evidence on learning styles and strategies that more readily translate into enduring behavior change. Adult education approaches are also careful to engage the learner as teacher, through a more egalitarian teaching relationship that shows respect for the life experience of adult learners. This style is naturally more culturally sensitive, as the teacher takes cues from the learner about family traditions and values (Merriam \& Brockett, 1996).

County extension educators bring their content expertise to the educational setting, so that some may specialize in nutrition or fitness, while others teach about family relations and parenting. However, extension educators in general, regardless of content expertise, have learned effective strategies to engage adult learners in transformational 
learning (U.S. Department of Agriculture, 2011). Adult learning is the specialty skill extension educators can bring to family support partnerships, complementing the talents and training of social workers.

Strong extension ties to land grant university campuses can bring other resources to a multi-disciplinary human services team. Many social service programs have outstanding front line staff, but few resources for research and evaluation. However, continued access to tax dollars or grant funds depends on strong evidence of program effectiveness. FCS extension educators can link programs to evaluation and data analysis expertise on campus to provide affordable, high quality program evaluation. Student engagement in such projects has added value, inspiring young adults' further interest in the human services and in small town and rural communities, and drawing future professionals to this area of critical need.

Like social workers and extension educators, community health nurses bring much-needed expertise to multidisciplinary family support teams. Many family support issues are evidenced in health outcomes, such as the compromised health of a malnourished child, or unexplained injuries from a violent home. Other family challenges stem from health issues, such as the difficulties of caring for a special needs child, or the resultant poverty when medical bills overtax family income.

Health services frequently serve as the front door to social services, as families reveal needs in the context of a health care visit. Health care settings can provide a neutral ground for families in need, particularly when working with known and trusted health professionals. Community-based nurses have the added advantage of their neighborhood-based family contacts, and the informal network of information they garner about family needs in the community.

Considering their extensive family needs, rural communities require strategic partnerships to provide the broadest possible network of support with limited resources. The potential power of a broad-based family support coalition will be explored through the example of grandparents raising grandchildren, a family form in strong evidence in rural America (Bigbee, Musil, \& Kenski, 2010).

\section{Community Partners and Grandparents Raising Grandchildren}

Family crisis can necessitate out of home placements to protect the children involved. A parent's long term physical or mental illness, substance abuse, incarceration, death, or military deployment, may require that children be cared for by others. Most commonly children are cared for by kin in informal arrangements made outside of the formal welfare system. For example, in Idaho in 2008 there were nine children in informal care with relatives for every one child in the foster care system (Shaklee, Bigbee, \& Wall, 2008). Families are the first line of defense in times of family crisis.

Most frequently, grandparents are the ones who step into the parenting role, caring for $59 \%$ of children in the U.S. living with kin. In fact, one in ten grandparents has been responsible for raising one or more grandchildren at some point in their lives (Fuller-Thomson \& Minkler, 2005). About 1/3 of U.S. grandparents raising grandchildren are over 60 years of age, $30 \%$ are not married, $30 \%$ have a disability, and nearly $20 \%$ live in poverty (Shaklee et al., 2008), all risk factors that point to a need for multi-faceted support for these families in transition.

Most relatives raising their kin are thrust into the role with little warning, when a family crisis comes to a head. A return to childrearing may necessitate major changes (Letiecq, Bailey, \& Porterfield, 2009), including work roles (e.g. returning to work to earn more income, or quitting work to take care of the children), housing (e.g. moving to a larger space to accommodate the children, or looking for less expensive space to free up funds for children's expenses), and family finances (e.g. extending family income to provide children's food, clothing, and child care).

Such major transitions in family structure come with emotional and social costs as well. Many grandparents lose their social networks when they take grandchildren into their homes, and report frustration with the loss of freedom and adult friendship (Hayslip \& Kaminski, 2005). Others are stressed as they navigate social service and legal systems in meeting family needs. Continued conflicts with the children's parents complicate the lives of grandparents raising grandchildren, along with frayed relationships with other family members. Family stress appears to be greatest in the first year of transition, with the quality of relationship with the grandchild mediating the course of the long term adjustments for caregiving grandparents (Goodman, 2012; Letiecq et al., 2009). 
The children in need of grandparent care often pose special challenges for their caregivers. Many children have lived in disorganized homes for years, with little parental guidance. Some have experienced prenatal exposure to drugs or alcohol as well. Family violence, neglect, poor nutrition, and irregular school attendance are common for children in need of out-of-home care. These life patterns may contribute to maladaptive behavior, attachment issues, poor school performance, mental illness, youth risk taking, substance abuse, and complex medical needs (Dubowitz, Feigelman, Zuravin, Tepper, Davidson, \& Lichenstein, 1992; Dubowitz, Zurvin, \& Star, 1993; Hayslip, Shore, Henderson, \& Lambert, 1998; Musil, Warner, Zauszniewski, Wylke, \& Standing, 2009).

All of these areas of challenge add up to a disruptive life for grandparenting families. A recent six month pilot health intervention found these significant stressors among the grandchildren, grandparents, and children's parents in seven rural families raising grandchildren: diagnoses of childhood diabetes, dropping out of high school, death, surgery, job loss, drug use, arrest, incarceration, and divorce (Bigbee, Vander Boegh, Prengaman, \& Shaklee, 2011).

Despite the challenges for children and grandparents, evidence suggests that kinship care may be the best resolution to a difficult situation for children. When parents are not able to fulfill their parental role, grandparents and other kin offer several advantages in child placement. Children living with relatives have more residential stability than those in foster placement with non-relatives, a factor associated with more positive outcomes for children. The children, themselves, report feeling less stigma in the homes of relatives than those with non-relatives (Pabustan-Claar, 2007; Simms, Dubowitz, Szilagyi, 2000). In addition, children in kinship placements are able to have more frequent, and regular visits with biological parents, maintain ties with siblings, experience fewer placement changes, as well as preserving racial and cultural ties (Green, 2003; Metzger, 2008).

In sum, grandparents and other kin have become the dominant refuge for children in crisis. The transitional issues for grandparents and the children point to a need for family support, but the nature of the family arrangements means that traditional social service providers may not have access to these families. Most caregiving grandparents are not formally designated foster parents, and the children's move to their grandparents' house takes place outside of the social service system. In fact, caregiving grandparents commonly express fear of the social service system, concerned that they'll lose the children to "the system," or become ensnarled in costly legal custody proceedings (Leticq et al., 2009). Under these circumstances, grandparenting families frequently pass under the radar of social service agencies.

Community nurses and extension educators may be able to serve as the front door to family support for grandparents raising grandchildren. County extension educators are familiar with a broad sector of the community, particularly in small towns and rural areas. Health professionals are also tuned into family circumstances, particularly community health nurses with their extensive community ties. The health needs of aging community members also bring grandparents into frequent contact with health care providers. Working in established coalitions alongside social work and mental health professionals, FCS extension professionals and community nurses can connect stressed grandparenting families to available resources in the community. The success of multidisciplinary coalitions in supporting these families points to the viability of this approach (Gandhavorn \& Hughes, 2007; Miller, Bruce, Bundy-Fazioli, \& Fruhauf, 2010).

They are also in a position to develop programs specifically to meet the needs of caregiving grandparents. Those grandparents who feel isolated from their former network of friends may find support from the grandparent support groups available in many communities, often sponsored by cooperative extension programs. The children involved may find friendship in their new community through the 4-H programs offered through the extension office (e.g. Ganthavorn \& Hughes, 2007; Miller et al., 2010).

Extension fitness and nutrition programs may also meet the needs of grandparents, who find they need more energy for their new responsibilities. Fitness activities can serve to moderate the stress experienced by grandparents as they work out the many adjustments to their new family form. In addition, the children in their care are relying on them for support for years to come - underscoring the importance of maximizing health outcomes when aging seniors return to the parenting role.

In fact, health interventions have been shown to be helpful to grandparents raising grandchildren. Home visitation programs targeting improved health have shown effects on physical, mental, and emotional health outcomes (Bigbee, et al., 2011; Kelley, Whitley, \& Campos, 2010). A program of health promotion, such as these for 
grandparents raising grandchildren, fits well with the mission and expertise of community health nursing and extension educator professionals, and is likely to be beyond the scope of work of most generalist social work practitioners.

This discussion shows the power of an expanded human services partnership to support overstressed rural families. In this case we have considered the many challenges of rural grandparents who take grandchildren into their homes. a broad-based multidisciplinary approach to family support including strategic cooperation of extension programs, community health nurses, and social workers can be effective in extending the reach of overburdened social service systems, maximizing service delivery and stimulating positive family outcomes. This strategy will be especially effective in rural and small town communities, where cooperative extension and community nursing personnel have such long roots in the community and provide a natural complement to social work philosophy and practice. 


\section{References}

American Psychological Association. (2012). The critical need for psychologists in rural America. Retrieved April 12, 2012 from http://www.apa.org/about/gr/education/rural-need.aspx

Bigbee, J. (1993). The uniqueness of rural nursing. Nursing Clinics of North America, 28(1), 131-144.

Bigbee, J., \& Crowder, E. (1985). The Red Cross rural nursing service: An innovative model of public health nursing delivery. Public Health Nursing, 2(2), 109-121.

Bigbee, J., Hampton, C, Blanford, D., \& Ketner, P. (2009). Community health nursing and cooperative extension: A natural partnership. Journal of Community Health Nursing, 26(4), 192-7.

Bigbee, H., Musil, C., \& Kenski, D. (2010). The health of caregiving grandmothers: A rural-urban comparison. Journal of Rural Health, 27, 289-296.

Bigbee, J., Vander Boegh, B., Prengaman, M., \& Shaklee, H. (2011). Promoting the health of frontier caregiving grandparents: A demonstration project evaluation. Journal for Specialists in Pediatric Nursing, 16, 156-61.

Bugenthal, D., Ellerson, P., Lin, E., Rainey, B., Kokotovic, A, \& O’Hara, N. (2002). A cognitive approach to child abuse prevention. Journal of Family Psychology, 16(3), 243-258.

Campbell, R., Greeson, M., Bybee, D., \& Raja, S. (2008). The co-occurrence of childhood sexual abuse, adult sexual assault, intimate partner violence, and sexual harassment: A mediational model of posttraumatic stress disorder and physical health outcomes. Journal of Consulting and Clinical Psychology, 76(2), 194207.

Carney, M \& Buttell, F. (2003). Reducing juvenile recidivism: Evaluating the wraparound services model, Research on Social Work Practice, 13, 551-568.

Center for Health Workforce Studies. (2006). Licensed Social Workers in Behavioral Health, 2004. Retrieved April 10, 2012 from http://workforce.socialworkers.org/studies/behavioral/behavioral_chap4.pdf

Condo, E. \& Martin, K. (2002. Health professions and cooperative extension: An emerging partnership. Journal of Extension, 40 (4), 4FEA2.DeBoard, K. (2005). Communicating program value of family life and parenting education programs to decision makers. Journal of Extension, 43(2), 2IAW2.

Dubowitz, H., Feigelman, S., Zuravin, S., Tepper, S., Davidson, H., \& Lichenstein, R. (1992). The physical health of children in kinship care. American Journal of Diseases in Children, 146, 603-610.

Dubowitz, H., Zurvin, S., \& Star, R. (1993). Behavior problems of children in kinship care. Journal of Developmental and Behavioral Pediatrics, 14, 386-93.

Fuller-Thomson, E., \& Minkler, M. (2005). American Indian/Alaskan Native grandparents raising grandchildren: Findings from the Census 2000 supplementary survey. Social Work, 50(2), 131-139.

Gais, T. (2009). Stretched net: The retrenchment of state and local social welfare spending before the recession. Publius, 39 (3), 557-579.

Gamm, L., Stone, S., \& Pittman, S. (2003). Mental health and mental disorders - A rural challenge: A literature review. Rural Healthy People 2010. Southwest Rural Health Research Center, College Station, TX.

Ganthavorn, C., \& Hughes, J. (2007). Promoting healthy lifestyles among grandparents raising grandchildren in Riverside County. Journal of Extension, 45(1), 1FEA6.

Goldberg, B., Frank, V., Bekenstein, S., Garriety, P., \& Ruiz, J. (2011). Successful community engagement: Laying the foundation for effective teen prevention. Journal of Children and Poverty, 17(1), 65-86.

Goodman, C. (2012). Caregiving grandmothers and their grandchildren: Well-being nine years later. Children and Youth Services Review, 34, 648-54.

Gray, M. E. (1990). Factors related to practice of breast self-examination in rural women. Cancer Nursing, 13(2), 100-107.

Green, R. (2003). Kinship care, Making the most of a valuable resource. Washington, D.C.: The Urban Institute Press.

Hall, C., Wimberly, P., Hall, J., Pfriemer, J., Hubbard, E., Stacy, A., \& Gilbert, J. (2005). Teaching breast cancer screening to African American women in the Arkansas Mississippi River Delta. Oncology Nursing Forum, 32(4), 857-863.

Hayslip, T., \& Kaminski, P. (2005). Grandparents raising their grandchildren: A review of the literature and suggestions for practice. The Gerontologist, 45, 262-269.

Hayslip, B., Shore, J., Henderson, C., \& Lambert, P. (1998). Custodial grandparenting and the impact of grandchildren with problems on role satisfaction and role meaning. Journal of Gerontology: Social Science, $53 B(3), 164-173$.

Hill, L., \& Parker, L. (2005). Extension as a delivery system for prevention programming: Capacity, barriers, and opportunities. Journal of Extension, 43(1), 1FEA1. 
Jenkins, S. (1991). The future of rural communities: Mobilizing local resources. In A. Bushy (Ed.) Rural Nursing, Volume 2. (pp 16-28). Newbury Park: Sage Publishing.

Kelley, S., Whitley, D., \& Campos, P. (2010). Grandmothers raising grandchildren: Results of an intervention to improve health outcomes. Journal of Nursing Scholarship, 42 (4), 379-86.

Lanier, P., Jonson-Reid, M., Stahlschmidt, M., Drake, B., \& Constantino, J. (2010). Child maltreatment and pediatric health outcomes: A longitudinal study of low-income children. Journal of Pediatric Psychology, 35(5), 511-522.

Letiecq, T., Bailey, S., \& Porterfield, F. (2009). "We have no rights, we get no help" The legal and policy dilemmas facing grandparent caregivers. Journal of Family Issues, 29(8), 995-1012.

Maine Rural Health Research Center (2007). Substance abuse among rural youth: A little meth and a lot of booze. Research and Policy Brief. Retrieved April 4, 2012 from muskie.usm.maine.edu/Publications/rural/pb35a.pdf

Maniglio, R. (2010). The impact of child sexual abuse on health: A systematic review of reviews. Clinical Psychology Review, 29(7), 647-657.

Martinez-Brawley, E. (2009). "The world is flat:' Is US rural social work flattening too? Rural Society, 19, $286-8$.

McDaid, D., \& Knapp, M. (2010). Black-skies planning? Prioritising mental health services in times of austerity. The British Journal of Psychiatry, 196, 423-4.

Merriam, S., \& Brockett, R. (1996). The profession and practice of adult education: An introduction. San Francisco: Jossey-Bass.

Metzger, J. (2008). Resiliency in children and youth in kinship care and family foster care. Child Welfare, $87(6), 115-140$.

Miller, J., Bruce, A., Bundy-Fazioli, K., \& Fruhauf, C. (2010). Community mobilization model applied to support grandparents raising grandchildren. Journal of Extension, 48(2), 2 IAW7.

Musil, C., Warner, C., Zauszniewski, M., Wylke, M., \& Standing, T. (2009). Grandmother caregiving, family stress and strain, and depressive symptoms. Western Journal of Nursing Research, 31(3), 389-408.

National Advisory Committee on Rural Health and Human Services. (2005). The 2005 report to the Secretary: rural health and human service issues. Retrieved March 22, 2012 from http://www.hrsa.gov/advisorycommittees/rural/2005secreport.pdf

National Advisory Committee on Rural Health and Human Services. (2007). The 2007 rReport to the Secretary: rural health and human service issues. Retrieved March 22, 2012 from http://www.hrsa.gov/advisorycommittees/rural/2007secreport.pdf

National Advisory Committee on Rural Health and Human Services. (2008). The 2008 report to the Secretary: rural health and human service issues. Retrieved March 22, 2012 from http://www.hrsa.gov/advisorycommittees/rural/2008secreport.pdf

Pabustan-Claar, J. (2007). Achieving permanence in foster care in young children: A comparison of kinship and non-kinship placements. Journal of Ethnic and Cultural Diversity in Social Work, 16(2), 61-94).

Prinz, R., Sanders, M., Shapiro, C., Whitaker, D., \& Lutzker, J. (2009). Population-based prevention of child maltreatment: The U.S. Triple P system population trial. Prevention Science, 10(1), 1-12.

Scribano, P. (2010). Prevention strategies in child maltreatment. Current Opinion in Pediatrics, 22(5), 616-620.

Shaklee, H., Bigbee, J., \& Wall, M. (2008). Grand families count in Idaho, Idaho Kids Count. Retrieved March 22, 2012 from www.idahokidscount.org.

Shaklee, H. \& Brown, J. (2009). Small Faces in a Big Recession, Idaho Kids Count: Quantitative Report, Retrieved July 25, 2012 from www.idahokidscount.org.

Simms, M., Dubowitz, H., \& Szilagyi, M. (2000). Health care needs of children in the foster care system. Pediatrics, 106, 909-918.

U.S. Department of Agriculture (2011). About Us: Extension, Retrieved July 26, 2012 from http://www.csrees.usda.gov/qlinks/extension.html

Wise, P. (2009). Children of the recession. Archives of Pediatric Adolescent Medicine, 163(11), 1063-4. 